\title{
Knowledge of the Digestive Microflora: Evaluation of Breastfeeding on the Establishment of the Gut Microbiota of the Newborn
}

\author{
Souad Bouchachia ${ }^{1,2}$, Hassiba Mahdjoub Bessam ${ }^{1,2}$ \\ ${ }^{1}$ Department of Biology, Faculty of Natural Sciences \& Life, Djillali Liabes University of Sidi Bel-Abbes, Sidi Bel-Abbes, Algeria \\ ${ }^{2}$ Laboratory Eco Development of Areas, Faculty of Natural Sciences \& Life, Djillali Liabes University of Sidi Bel-Abbes, Sidi Bel-Abbes, \\ Algeria
}

Email address:

tek6-6hl@hotmail.fr (S. Bouchachia)

\section{To cite this article:}

Souad Bouchachia, Hassiba Mahdjoub Bessam. Knowledge of the Digestive Microflora: Evaluation of Breastfeeding on the Establishment of the Gut Microbiota of the Newborn. Journal of Food and Nutrition Sciences. Vol. 4, No. 4, 2016, pp. 86-90.

doi: $10.11648 /$ j.jfns.20160404.12

Received: May 24, 2016; Accepted: June 2, 2016; Published: June 17, 2016

\begin{abstract}
At birth, the newborn has no bacteria in its gut. This last is rapidly colonized by microbial flora (microbiota) from, mainly of the mother and environment. The main objective is the study of the influence of breastfeeding in the establishment of the intestinal microbial flora in the newborn. The secondary objective of this work was to analyze the bacterial diversity in feces of breast-fed infants and to compare it with that of formula-fed ones. Five pairs of mother-child and 5 fed formula have participated in the study. The Samples were taken at 1, 7,30 and 90 days and plated out on various culture media. The present study shows that breast milk plays a major role in the development of the intestinal microbiota of the child. The results of this comparative study showed that the fecal matter of a mother breast-fed infants are more rich in probiotics and less rich in pathogenic bacteria that infants receiving infant formula.
\end{abstract}

Keywords: Microbiota Intestinal, Newborn, Breastfeeding, Breast Milk, Infant Formula, Probiotic, Lactic Acid Bacteria

\section{Introduction}

The human body is inhabited by numerous bacteria located mainly in the intestine known as the gut microbiota [1]. The intestinal microbiota contains approximately $10^{14}$ bacteria in 4 bacterial phyla: the Firmicutes, Bacteroidetes, Actinobacteria, and Proteobacteria [2]. Intestinal bacteria colonize our gut in the first hours of life and form an early ecosystem remarkably stable throughout life [3]. The newborn, sterile at birth, is colonized with flora from contact with his mother and environment [4]. Human milk represents one of the main factors that play a critical role in influencing infant's microbiota composition, also being a direct source of microbes [5]. Research over the past decade has confirmed the essential role of breast milk in the establishment a healthy intestinal microbiota within the infant [6].

The main objective of this work is the study of the influence of breastfeeding on the development of the intestinal microbial flora of newborn. The secondary objective of this study is to identify the constituent strains of bacteria of the intestinal flora in infants breastfed and bottle, in order to control the behavior of different microbial flora.

\section{Materials \& Methods}

\subsection{Plan of Study and Subjects}

This study was conducted between May 2014 and December 2015. Five mother-child pairs were recruited to establish Mother-Child. Five healthy women (mean age 33.2 \pm 4.53) were enrolled after delivery in the establishing Mother-Child.

\subsection{Collection of Sample}

Breast milk samples (5 women) and feces of infants (5 infants) were collected at 1.7, 30 and 90 days. Breast-milk samples were obtained by manual expression after cleaning the nipples and areola by wiping with a swab soaked in 
sterile water and discarding the first drops.

All Infants: 5 Newborn breastfed maternally (3 Boys / Girls 2) and 5 infants fed formula were born in the hospital neonatal unit after an uncomplicated pregnancy. Infants were vaginally delivered, at a gestational age of 39.2 weeks. None of the mothers or babies received antibiotic therapy during the sampling period.

\subsection{Microbial Counts}

\subsubsection{Microbiological Analyzes}

Samples were taken to the laboratory at $4-5^{\circ} \mathrm{C}$ using a cooler and stored in the laboratory refrigerator at $4^{\circ} \mathrm{C}$ until use.

Lactobacilli were enumerated on MRS medium (ManRogosa-Sharpe) incubated at $37^{\circ} \mathrm{C}$ for $72 \mathrm{~h}$ anaerobically. The enumeration of streptococci and enterococci were performed on $\mathrm{M} 17$ medium incubated at $37^{\circ} \mathrm{C}$ and $42^{\circ} \mathrm{C}$ for 48 hours under aerobic conditions [7].

Bifidobacteria were enumerated on MRS medium supplemented with L-cysteine ( $0.5 \mathrm{~g} /$ liter $)$, which were incubated anaerobically at $37^{\circ} \mathrm{C}$ for $48 \mathrm{~h}$ [8].

Staphylococci are counted on Chapman agar. The incubation was carried out 48 hours at $37^{\circ} \mathrm{C}$. The enumeration of yeasts and molds on the classic Sabouraud medium. Incubation was carried out for 5 days at $37^{\circ} \mathrm{C}$ [9].

\subsubsection{Identification of Isolates}

Regarding the different identifications and confirmations of lactic acid bacteria, using two first types of galleries: API 20 STREP (API 20 Strep, Bio Merieux, France) and API 50 CHL gallery (API 50 CHL, Bio Merieux, France) with their boxes of reagents. API Staph system was evaluated as a means for identifying staphylococci species and for identification of enterobacteria, using the API $20 \mathrm{E}$. Then we used the identification catalogs for confirmation and then the API Web ${ }^{\mathrm{TM}}$ software (Bio Mérieux, France).

\subsubsection{Statistical Analyses}

All bacterial counts were analyzed after $\log 10$ transformation. Bacteria levels in samples of breast milk and infant faeces who received breast milk and those who received formula milk was compared using the $t$-test. Statistical analysis was performed using SPSS 19.0 software (SPSS Inc., Chicago, IL, USA) and the Excel 2007 software. The statements of statistics were considered to be significant when $P<0.05$.

\section{Results}

\subsection{The Influence of Breastfeeding in the Establishment of the Microbial Flora of the New Born}

From day 1 of bacterial counts, there is a microbial diversification in milk after microbiological analyzes revealed the presence of Streptococcus and Enterococcus at $37^{\circ} \mathrm{C}$ to value $3 \log \mathrm{CFU} / \mathrm{g}$ to $3.57 \log \mathrm{CFU} / \mathrm{g}$ with a percentage of $65.96 \%$ and $11.31 \%$ at $42^{\circ} \mathrm{C}$, respectively. The presence of Streptococcus in fecal samples first day varies between $2.69 \log \mathrm{CFU} / \mathrm{g}$ to $3.84 \log \mathrm{CFU} / \mathrm{g}$, a nonsignificant result was observed $(P=0.83)$.

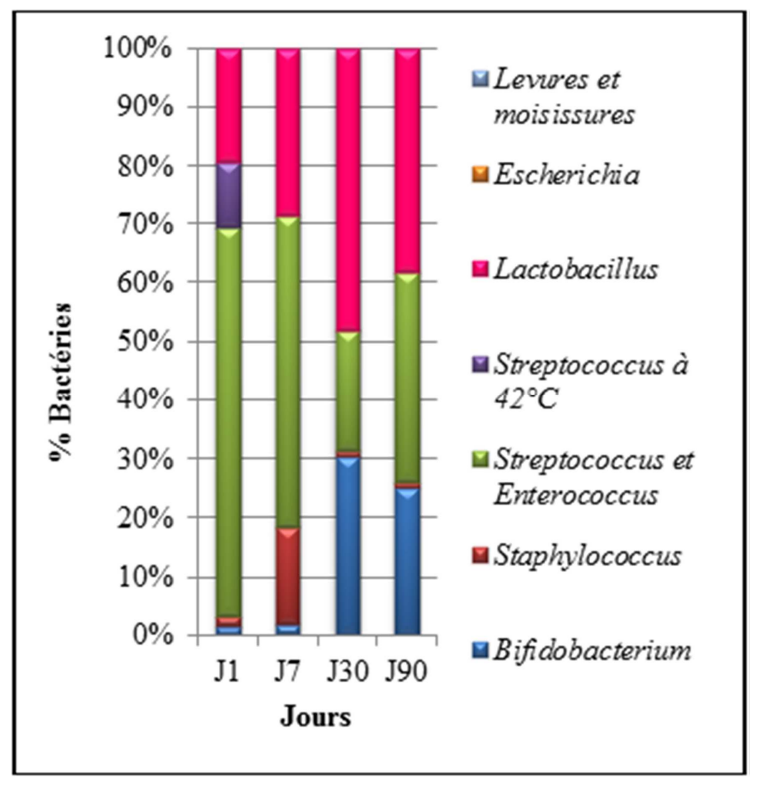

(a)

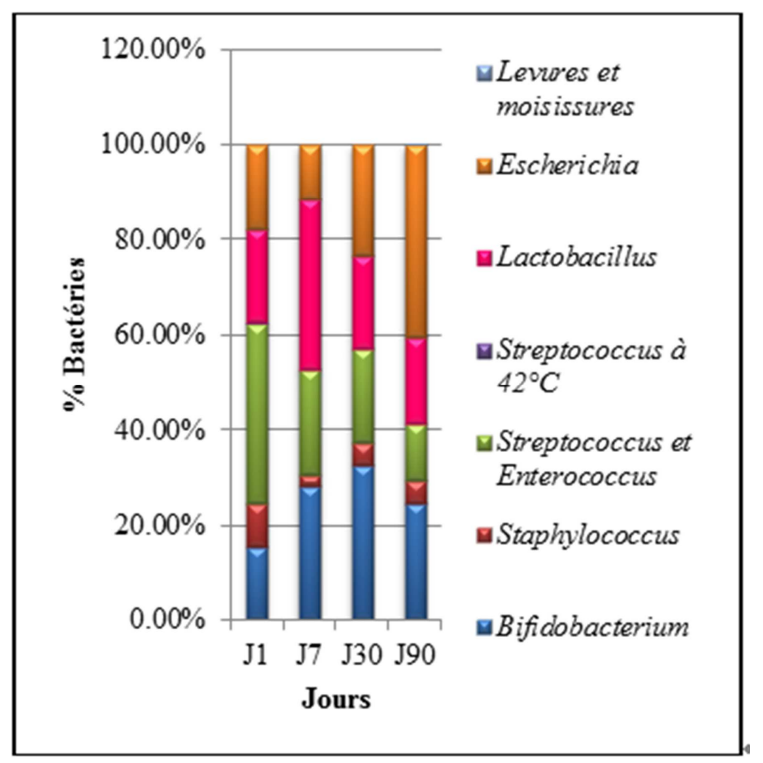

(b)

Figure 1. The percentages of isolation of different bacterial genera in the breast milk (A) and infant feces (B) at different sampling points analyzed.

Bifidobacterium rate in milk varies between $1.55 \log$ CFU $/ \mathrm{g}$ up to $2 \log \mathrm{CFU} / \mathrm{g}$ with a percentage of $1.56 \%$ and faeces varies between 0 to $3.61 \mathrm{log} \mathrm{CFU} / \mathrm{g}$ with a percentage of $15.36 \%$. Lactobacillus rate ranges from 0 to $3.40 \log$ CFU / g with a percentage of $19.39 \%$ in breast milk and 0 to $3.74 \log$ $\mathrm{CFU} / \mathrm{g}$ in infant faeces, with a percentage of $19.50 \%$. It does there was no significant difference $(P>0.05)$ on bifidobacteria and lactobacillus.

Concerning pathogenic bacteria Escherichia absence is observed in milk and percentage of $18.00 \%$ in the faeces, a statistically significant $(\mathrm{P}=0.009)$. The presence of 
Staphylococcus to a value of 1.86 to $2.17 \log \mathrm{CFU} / \mathrm{g}$ with a percentage of $1.76 \%$ in the milk and 0 to $3.47 \mathrm{log} \mathrm{CFU} / \mathrm{g}$ with percentage of $9.12 \%$ in the feces.

On the seventh day there is an increase in the Bifidobacterium and Lactobacillus rate of $28.17 \%$ and $35.72 \%$ respectively in infant faeces, the difference is not statistically significant $(P=0.98 ; P=0.55)$

The $30^{\text {th }}$ day reduction in Streptococcus rate observed in milk and feces with a percentage of $20.50 \%, 19.90 \%$ respectively. An increase of Escherichia in faeces (23.25\%). It is there fore considered statistically significant $(P=0.009)$ The $90^{\text {th }}$ day there is a lack of yeasts and molds in milk and presence in feces $(P<0.05)$, about pathogenic bacteria a significant result was observed $(P<0.05)$ (Figure 1).

The strains isolated from breast milk are:

Leuconostoc spp, Streptococcus anginosus, Streptococcus salivarius, Lactococcus lactis ssp cremoris, Staphylococcus hominis, Bifidobacterium spp, Lactobacillus paracasei ssp paracasei 1, Lactobacillus acidophilus 1, Lactobacillus delbrueckii ssp delbrueckii, Leuconostoc mesenteroides ssp cremoris.

Among the strains isolated from feces for infants, there is a predominance of Enterococcus faecalis and Enterococcus faecium.

\subsection{The Evaluation of the Intestinal Flora of Breastfed Infants of a Mother and Breastfed Infants with Formula Milk}

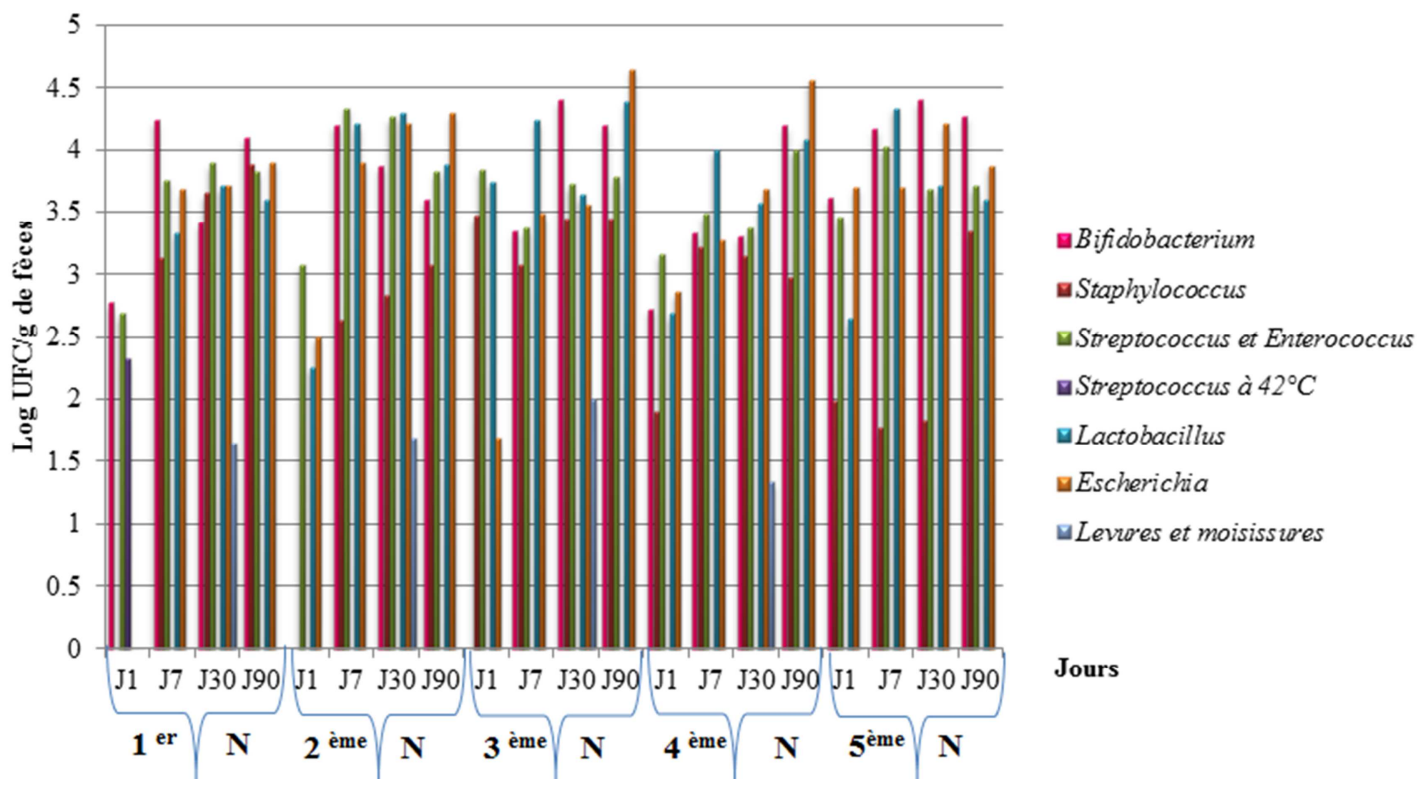

$\mathrm{N}$ : Infants

Figure 2. Counting result of fecal flora of the 5 infants breastfed maternally.

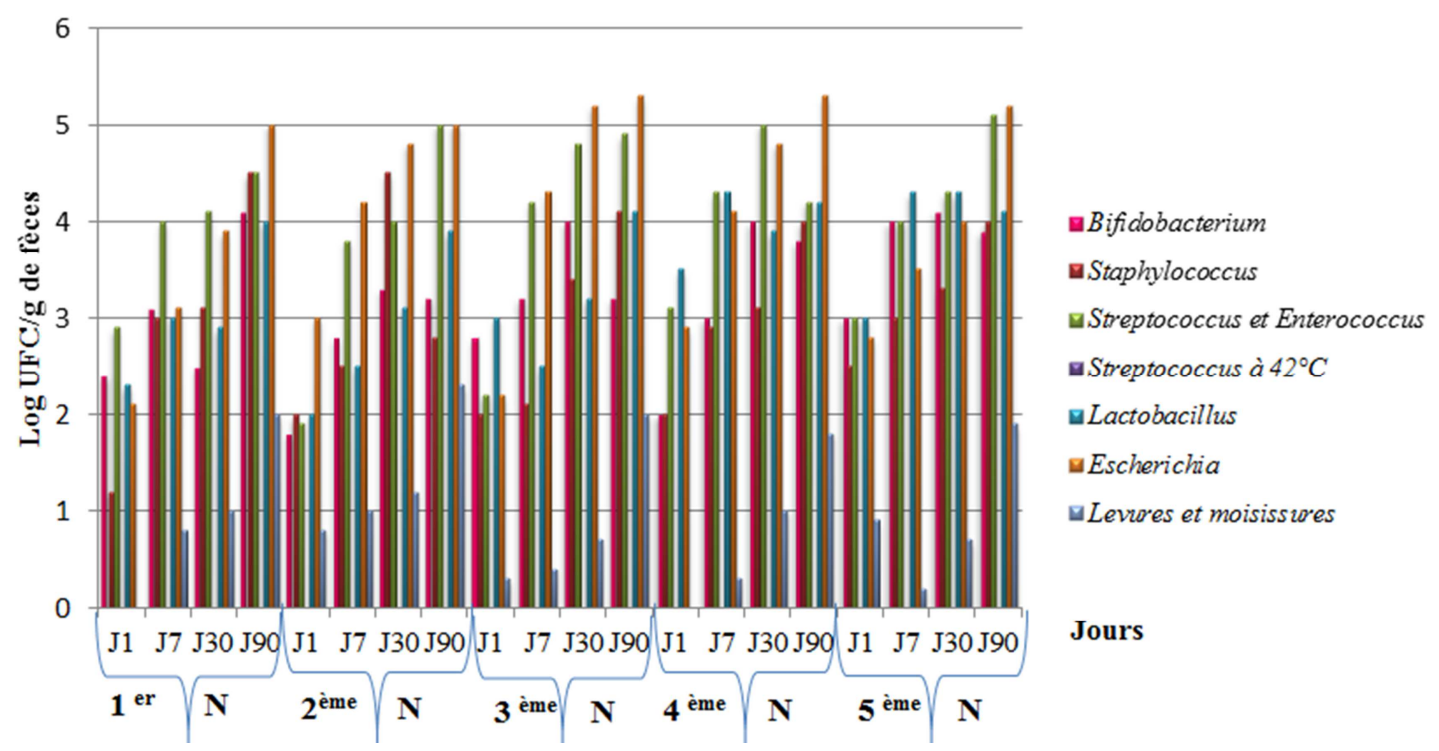

Figure 3. Counting result of fecal flora of breastfed infants 5 artificially. 
Maternally breastfed infants, bifidobacteria, having their maximum during their first month of life with values $4.4 \mathrm{log}$ CFU / g of feces (Figure 2). In infants receiving infant formula, bifidobacteria are at rates varying between 2 to 4 $\log$ CFU / g for 90 days.

However, the bacterial genus Escherichia is in faeces artificially breastfed infant during the first month at high rates around $5.2 \log \mathrm{CFU} / \mathrm{g}$, Interestingly, in the sampling point first found statistically significant differences in the levels of Escherichia between maternally breastfed and those who did not after the $30^{\text {th }}$ day and $90^{\text {th }}$ day $(3.86 \pm 0.3,4.54 \pm$ $0.5 ; 4.25 \pm 0.36,5.16 \pm 0.15$, respectively)

Low quantities of the Staphylococcus genus are recorded on the first day of life for all breastfed infants maternally at $0 \mathrm{Log}$ $\mathrm{CFU} / \mathrm{g}$ of feces first infant then this amount increases over the days to neighboring values $3.88 \log \mathrm{CFU} / \mathrm{g}$ after the third month of life. However staphylococci are at much higher for infants fed formula milk and it increases over the month to reach higher values of about $4.5 \log \mathrm{CFU} / \mathrm{g}$ on the $90^{\text {th }}$ day of the first infant receiving artificial milk. (Figure 3).

\section{Discussion}

Improve our understanding of gut microbiota could be useful to better understand the roles of microbial strains in promoting the health of infants [10]. Colostrum and milk play a key role in the initiation, development and composition of infant intestinal microflora [11].

The interesting observation of West et al. [12] that breast milk is not sterile even when collected aseptically. An independent and dependent analysis of the culture of human milk samples revealed the presence of the genus Streptococcus and Staphylococcus, which corresponds to the first colonizers of the digestive tract [13].

Martin and his colleague (2003) showed that the same strains of lactic acid bacteria in breast milk are also present in the faeces of the infant [14].

This study confirms our results find that the same lactic strains such as Bifidobacterium spp, Lactobacillus paracasei ssp paracasei 1, Lactobacillus acidophilus 1, Lactobacillus delbrueckii ssp delbrueckii, Leuconostoc mesenteroides ssp cremoris found in breast milk and infant feces.

$L$. delbrueckii and $L$. reuteri, were among the most frequently isolated bacteria in fecal samples obtained from Swedish infants during the first year of life [15].

In the works of De Leoz et al. [16] the rate of Bifidobacterium is noticed after the $13^{\text {th }}$ week of life infants, confirming the absence of Bifidobacterium in some infants in this study.

The microbiological analysis of breast milk levels of Streptococcus reveals the presence of high levels, agree with Solis et al. [17] with a percentage of $65 \%$ Streptococcus is the first day and $50 \%$ on the $90^{\text {th }}$ day.

Indeed, Schultz et al. [18] confirmed such a transmission of probiotic strains from mother to child during birth; although the specific probiotic strain was present in very low numbers $\left(10^{4}-10^{5} \mathrm{CFU} / \mathrm{g}\right.$ feces $)$ for most infants, it persisted at least until the age of 6 months.

A recent hypothesis suggests a novel way of motherneonate communication, in which maternal gut bacteria reach breast milk via intestinal translocation and blood carriage, describing an internal entero-mammary pathway to influence neonatal gut colonization and maturation of the immune system. This novel pathway of bacterial transfer would support the addition of carefully selected bacteria from mother's breast milk to formula and opens new windows of opportunity for designing probiotics tailored to the infant. [19]

A few hours after birth, babies are colonized by bacteria and develop their normal bacterial microflora [20,21], by type of food and closely associated with the environmental microflora [20].

Enterococcus faecalis was the second bacterial species prevalent in fecal samples provided by nursing infants, but it was present in all samples of those bottle-fed [22]. This study confirms our findings that finds an abundance of Enterococcus faecalis in fecal samples in both groups.

The present study shows the abundance of potentially pathogenic bacteria such as Escherichia, Staphylococcus in feces of infants receiving infant formula compared to infants breastfed maternally feces is due not only to the rich breast milk by specific factors that promote the growth of potentially beneficial bacteria and inhibit the potentially pathogenic germs.

Similarly, the work of two researchers Bezirtzoglou and Stavropoulou [23] show that breastfed infants maternally an acidic environment in the intestinal lumen "acetate buffer' suggesting that this acid has a bacteriostatic effect on potentially pathogenic germs especially against bacteria gram-negative.

\section{Conclusion}

The intestinal microbiota is now considered a full body finely interacting with the host. Research on these commensal bacteria in recent years is growing but many roles remain to be discovered [24]. Our results indicate that breast milk contains Lactobacillus and Bifidobacteria that could contribute to the establishment and development of microbial flora in the newborn. The present study shows that breast milk plays a major role in the development of the intestinal microbiota of the child. The results of this comparative study showed that the fecal matter of a mother breastfed infants are more rich and less rich probiotic bacterial pathogens that infants receiving infant formula. Micro organisms isolated in this study may be promising strains for inclusion in infant formula. The application of molecular ecology tools intestinal microbiota led to very significant improvements in our understanding of this ecosystem, in terms of composition and dynamics of species diversity. 


\section{References}

[1] Omenetti, S., Pizarro, T. T. The Treg/Th 17 axis: a dynamic balance regulated by the gut microbiome. (2015). Front Immunol, 6, 639.

[2] Quévrain, E., Seksik, P. Microbiote intestinal: de la diarrhée post-antibiotiques aux maladies inflammatoires intestinales. (2013). Presse Med, 42: 45-51.

[3] Rigottier-Gois, L., Meylheuc, T. Microbiote intestinal, nouvel organe au potentiel extraordinaire. (2013). INRA.

[4] Campeotto, F., Waligora-Dupriet' A., J., Doucet-Populaire' F., Kalach, N., Dupont' C., Butel, M., J. (2007). Mise en place de la flore intestinale du nouveau-né. Gastroentérologie clinique et biologique, 31, 533-542.

[5] Thum, C., Cookson, A. L., Otter, D. E., McNabb, W. C., Hodgkinson, A. J., Dyer, J., Roy, N. C. Can nutritional modulation of maternalintestinal microbiota influence the development of the infantgastrointestinal tract? (2012). J Nutr, $142,1921-8$.

[6] Goldsmith, F., O’ Sullivan, A., Smilowitz, J. T., Freeman, S. L. (2015). Lactation and Intestinal Microbiota: How Early Diet Shapes the Infant Gut. J Mammary Gland Biol Neoplasia (2015) 20: 149-158.

[7] Oxoid 2007. www.oxoid.com.

[8] Martin, R., Jimenez, E., Heilig, H., Fernandez, L., Marín, M. L., Zoetendal, E. G., \& Rodriquez, J. M. (2009). Isolation of Bifidobacteria from Breast Milk and Assessment of the Bifidobacterial Population by PCR-Denaturing Gradient Gel Electrophoresis and Quantitative Real-Time PCR. Applied and environmental microbiology, 965-969. doi: 10.1128/AEM.02063-08.

[9] Delarras, C. (2007). Microbiologie pratique pour le laboratoire, d'analyse ou de contrôle sanitaire. Lavoisier. p 323-367.

[10] Johnson, C. L, \& Versalovic, J. (2012). The human microbiome and its potential importance to pediatrics. Pediatrics, 129, 950-60.

[11] Heikkila“, M. P., \& Saris, P. E. J. (2003). Inhibition of Staphylococcus aureus by the commensal bacteria of human milk. Journal of Applied Microbiology, 95, 471-478.

[12] West, P. A., Hewitt, J. H., \& Murphy, O. M. (1979). The influence of methods of collection and storage on the bacteriology of human milk. J. Appl. Bacteriol, 46, 269-277.

[13] Collado, M. C., Delgado, S., Maldonado, A., \& Rodriguez, J. M. (2009). Assess- ment of the bacterial diversity of breast milk of healthy women by quantitative real-time PCR. Lett Appl Microbiol, 48, 523-8.

[14] Martin, R., Langa, S., Reviriego, C., Jimenez, E., Marin, M. L., Xanus, J., Fernandez, L., \& Rodriquez, J. M. (2003). Human milk is a source of lactic acid bacteria for the infant gut. J Pediatr, 143 (6), 754-8.

[15] Ahrne, S., Lonnermark, E., Wold, A. E., Aberg, N., Hesselmar, B., Saalman, R., Strannegard, I. L., Molin, G.,\& Adlerberth, I. (2005). Lactobacilli in the intestinal microbiota of Swedish infants. Microbes Infect, 7 (11-12), 1256-1262.

[16] De Leoz, M. L. A., Kalanetra, K. M., Bokulich, N. A., Strum, J. S., Underwood, M. A., German, J. B., Mills, D. A., \& Lebrilla, C. B. (2015). Human Milk Glycomics and Gut Microbial Genomics in Infant Feces Show a Correlation between Human Milk Oligosaccharides and Gut Microbiota: A Proof-of-Concept Study. | J. Proteome Res, 14, 491-502. dx. doi. org/10.1021/pr 500759e.

[17] Solís, G., de los Reyes-Gavilan, C. G., Fernández, N., Margolles, A., \& Gueimonde, M. (2010). Establishment and development of lactic acid bacteria and bifidobacteria microbiota in breast-milk and the infant gut. Anaerobe, 16, 307-310. doi: 10.1016/j.anaerobe.2010.02.004.

[18] Schultz, M., Gottl, C., Young, R. J., Iwen, P., \& Vanderhoof J. A. (2004). Administration of oral probiotic bacteria to pregnant women causes temporary infantile colonization. J Pediatr Gastroenterol Nutr, 38, 293-297.

[19] WHO: Health and nutritional properties of probiotics in food including powder milk with live lactic acid bacteria a joint FAO/WHO expert consultation. 2001.

[20] Bezirtzoglou, E., Romond, B. M., \& Romond, C. (1992). Regulation of the bacterial intestinal implantation in infant born by cesarian section. Comp Immunol Microbiol Inf Dis, 115 (1), 71e4.

[21] Bezirtzoglou, E., \& Romond, C. (1990). Occurrence of Bifidobacterium in the feces of newborns delivered by ceasarean section. Biol Neonate, 58 (5), 247-51.

[22] Jiménez, E., Delgado S., Maldonado, A., Arroyo R., Albújar, M., García, N., Jariod, M., Fernández, L., Gómez, A., \& Rod ríguez, J. M. (2008). Staphylococcus epidermidis: A differential trait of the fecal microbiota of breast-fed infants. BMC Microbiology, 8: 143. doi: 10.1186/1471-2180-8-143.

[23] Bezirtzoglou, E., \& Stavropoulou, E. (2010). Immunology and probiotic impact of the newborn and young children intestinal microflora. Clinical Microbiology, 17, 369-374.

[24] Nicolas, S. (2016). Impact du microbiote intestinal sur le développement des allergies. Revue française d'allergologie, $56,133-134$. 